planations", which are hard to handle on conventional database systems. ICOT have already loaded some GenBank databases into Kappa by accessing the DNA Data Bank of Japan (DDBJ) in Mishima.

Ross Overbeek, senior scientist at Argonne, says that in the next few months the US-Japanese team will select a small number of specific projects as prototypes to demonstrate the significance of the emerging computer technology for the human genome project.

At first, only about ten researchers (four or five on each side) will be directly involved. But in future Overbeek says the team hope to form a much wider collaboration involving US and Japanese biologists.

As examples, Overbeek points out that Argonne is establishing a centre for analysis of ribosomal sequence data with Carl Woese's group at the University of Illinois. The laboratory is also working on the integration of data from multiple biological databases with Toni Kazic of
Washington University.

ICOT researchers are finding it much harder to find Japanese biologists with whom to cooperate. Uchida says each Japanese biologist seems to have his own philosophy on computer use and he has found only three or four people who have shown an interest in the application of logic programming to genome data. But among his allies are researchers at DDBJ and people involved in drawing up plans for a human genome project for the Ministry of Education, Science and Culture.

The Argonne-ICOT project will initially run until March 1992 when the fifthgeneration computer project is scheduled to end. Kazuhiro Fuchi, director of ICOT, says that MITI has only just begun discussing the future of ICOT. One possibility is to close the institute, or it could be continued in a "new style", he says.

And Fuchi is clearly encouraging Uchida and his co-workers at ICOT to develop the collaboration with Argonne into something bigger. David Swinbanks

\section{Still too hot to touch?}

Munich

AN international team of experts is to visit the area around Chernobyl to assess illeffects on the health of the local population and environment from radiation released in the 1986 nuclear accident. The investigation, announced by the International Atomic Energy Agency (IAEA) last month, is a response to a Soviet request to IAEA made in October 1989, and will also evaluate the measures taken by the Soviet government to cope with contamination.

IAEA will report late in 1990 . The Food and Agricultural Organization, the European Commission, the United Nations Scientific Committee on the Effects of Atomic Radiation and the World Health Organization are helping with the study.

Severe malformations of local flora and fauna have been blamed on radiation from Chernobyl, but these anecdotal reports do not accord with what is known of the aftereffects of the Hiroshima and Nagasaki explosions.

Steven Dickman

\title{
An offer Japan can refuse
}

\section{Tokyo}

IN an attempt to tease from the Japanese government its help in building the Superconducting Super Collider (SSC), a team from the US Department of Energy (DOE) last week suggested that Japanese industry might be allowed to build as many as half of the accelerator's 10,000 superconducting magnets in return for a contribution to the project's $\$ 8,000$ million construction costs. But the offer failed to elicit any firm commitment from Japan, and is not likely to go down well with the US Congress either.

The superconducting magnets were on a list of nine items shown to representatives of the Science and Technology Agency (STA), the Ministry of Education, Science and Culture (MESC), the Ministry of Foreign Affairs and the Ministry of International Trade and Industry (MITI) as examples of technologically advanced devices that Japan might be interested in providing. Also included was equipment for the SSC's particle detectors, whose billion-dollar cost is not included in the $\$ 8,000$ million price. At a press conference on 4 June, DOE officials refused to reveal details of the list, but it was seen by a member of the Japanese press who passed the information onto Nature.

But the technological items that might attract Japanese interest are the same ones whose manufacture the US Congress has insisted, so far, should remain in the United States (see Nature 345, 375; 1990). Nevertheless, Henson Moore, DOE deputy secretary and head of the US dele- gation, said "should the Japanese government decide it would like to contribute by providing the magnets, Congress would support such a move".

No quick decision can be expected from the Japanese government because of wrangling between the various ministries and agencies involved and because of limitations on their budgets.

Traditionally MESC has been in charge of Japan's major high-energy physics projects, such as the positron-electron collider TRISTAN in Tsukuba. But recently, STA has begun to encroach on MESC territory with plans to build a huge $8 \mathrm{GeV}$ synchrotron near Osaka.

Toichi Sakata of STA, who met the US delegation, stresses that the SSC should fall under the responsibility of MESC for "historical" reasons. But Yubun Narita, director of scientific affairs at the Ministry of Foreign Affairs, says that no decision has been made on which government agency should take the lead.

For a variety of reasons, MESC is most unlikely to come forward with the sort of money (about $\$ 1,600$ million) that DOE is seeking from foreign partners. The ministry is very conservative and has no precedent for contributing such large sums of money to a foreign project. In addition, Japanese high-energy physicists affiliated to MESC are divided in their opinions about the SSC.

Some researchers at the High Energy Physics Laboratory (KEK) in Tsukuba are collaborating with their US colleagues in drawing up plans for the SSC. But others, at KEK and at Tokyo, Kyoto and Nagoya universities, have no intention of actively participating.

In particular, Tokyo University researchers would prefer to continue their collaboration with Europe on the OPAL experiment on the LEP electron-positron collider at CERN and on CERN's Large Hadron Collider (LHC) - if it is built.

Furthermore, many high-energy physicists want MESC to fund a huge linear collider, the Japan Linear Collider (JLC), which would have many of the same scientific goals as the SSC (see Nature 344, 8; 1990). The proposed JLC is an electron-positron collider, unlike the SSC which will collide protons, and although it is of lower energy than the SSC, Japanese scientists believe the JLC will provide cleaner and superior results. But if MESC were to contribute to the construction costs of the SSC, the JLC project would be in jeopardy.

Nor does it seem likely that STA could fund SSC construction because any move to make STA the lead agency is likely to be opposed by MESC-affiliated physicists who want to participate in the experimental phase of the SSC.

Despite all these problems, Henson Moore says that after his discussions with the various ministries and agencies he is "optimistic" that Japan will join the project, because he says Japanese participation would give meaning to the recent agreement between Prime Minister Toshiki Kaifu and President George Bush for the two countries to form a "global partnership".

Discussion of Japanese participation is likely to move forward only if it is taken up at the highest level of the Japanese government. 